\title{
Percepção da educação permanente, continuada e em serviço para enfermeiros de um hospital de ensino*
}

\author{
THE PERCEPTION OF PERMANENT, CONTINUOUS, \\ IN SERVICE EDUCATION FOR NURSES IN A SCHOOL HOSPITAL
}

\author{
LA PERCEPCIÓN DE LA EDUCACIÓN PERMANENTE, CONTINUADA \\ Y EN SERVICIO PARA EL ENFERMERO DEL HOSPITAL DE ENSEÑANZA
}

Amarílis Schiavon Paschoal ${ }^{1}$, Maria de Fátima Mantovani ${ }^{2}$, Marineli Joaquim Méier ${ }^{3}$

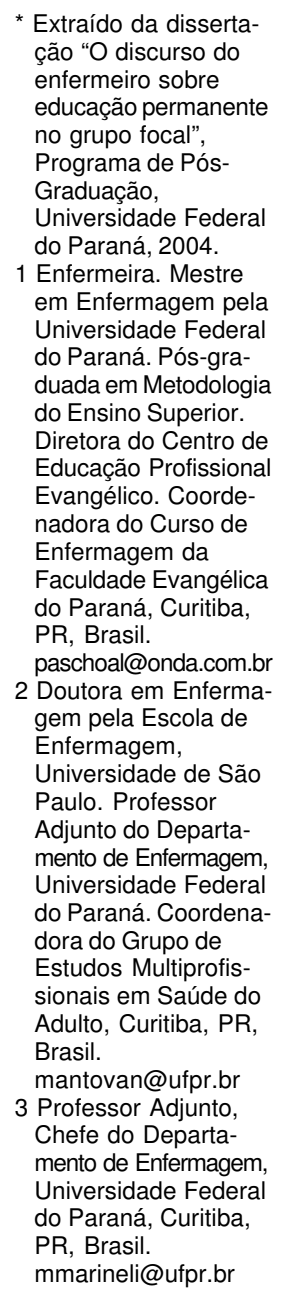

\section{RESUMO}

Este estudo tem como objetivo discutir a concepção de educação permanente, continuada e em serviço junto a enfermeiros de um hospital de ensino. É uma pesquisa de natureza qualitativa, na qual a coleta dos dados foi realizada pela técnica do grupo focal, durante seis sessões gravadas em áudio e vídeo. Participaram deste estudo nove enfermeiros de um hospital de ensino. Para analisar os dados, utilizou-se a técnica do discurso do sujeito coletivo, que consiste na organização e tabulação de dados qualitativos de natureza verbal obtidos por meio de depoimentos, da qual resultou um único discurso. A pesquisa demonstrou que os enfermeiros diferenciaram os termos educação permanente, continuada e em serviço, construindo conceitos próprios, ressaltando a importância da diferenciação para definir o tipo de ação a ser tomada diante da necessidade educativa apresentada.

\section{DESCRITORES}

Educação em enfermagem. Prática profissional. Educação continuada.

\section{ABSTRACT}

This study is aimed at discussing the conception of permanent, continuous, in service education among nurses at a school hospital. It is a research of qualitative nature, for which the data was gathered using the technique of focal group in six sessions recorded in audio and video. Nine nurses of a school hospital took part in it. For the analysis of the data was used the technique of collective subject speech, which consists of the organization and computation of the qualitative data of oral nature recorded, from which resulted a single speech. The research showed that the nurses differentiated the terms permanent education, continuous education and in service education, building their own concepts, highlighting the importance of differentiation in order to define the kind of approach to be taken to address the educative need presented.

\section{KEY WORDS}

Education, nursing.

Professional practice.

Education continuing.

\section{RESUMEN}

Este estudio tiene como objetivo la discusión de la concepción de los términos de la educación permanente, continuada y en servicio con enfermeros del hospital de enseñanza. Es una investigación de naturaleza cualitativa, en que fueron recogidos los datos a través de la técnica del grupo focal, durante seis sesiones grabadas en audio y video. Participaron de este estudio nueve enfermeros de un hospital de enseñanza. Para analizar los datos fue utilizada la técnica del discurso del sujeto colectivo, que consiste en la organización y tabulación de datos cualitativos de naturaleza verbal obtenidos por medio de deposiciones, que resultó de un único discurso. La investigación demostró que los enfermeros diferenciaron los términos educación permanente, continuada y en servicio, construyendo conceptos propios, resaltando la importancia de la diferenciación para definir el tipo de acción a ser tomada delante de la necesidad educativa representada.

\section{DESCRIPTORES}

Educación en enfermería.

Práctica profesional.

Educación continua. 


\section{INTRODUÇÃO}

A educação é um fenômeno social e universal, sendo uma atividade humana necessária à existência e ao funcionamento de toda a sociedade, portanto esta precisa cuidar da formação de seus indivíduos, auxiliando-os no desenvolvimento de suas capacidades físicas e espirituais e preparálos para a participação ativa e transformadora nas várias instâncias da vida social ${ }^{(1)}$. Apesar disso, a educação não é apenas uma exigência da vida em sociedade, mas também é o processo para prover os sujeitos do conhecimento e das experiências culturais, científicas, morais e adaptativas que os tornam aptos a atuar no meio social, mundial e planetário, ou seja, ela depende da união dos saberes.

Apesar de depender da união dos saberes, o que existe hoje é a fragmentação total da educação, há separação em duas linhas: de um lado, a escola, dividida em partes, de outro lado, a vida, na qual se desenvolve o sujeito e os pro-blemas são cada vez maismultidisciplinares, globais e planetários. Neste contexto, a falta de complexidade na educação - complexidade entendida aqui como abrangência, profundidade - prejudica o conhecimento e as informações decorrentes da educação recebida durante a vida ${ }^{(1)}$.

Além da afirmação acima menciona-se que o homem deve ser sujeito de sua própria educação, não pode ser objeto dela ${ }^{(2)}$, isto implica em uma busca contínua do homem, como um ser ativo na construção do seu saber, responsabilizando-se por sua educação, procurando meios que o levem ao crescimento e aperfeiçoamento de sua capacidade. pode ser percebida em diferentes vertentes e situações tais como: educação permanente, educação continuada e educação em serviço. O interesse em entender como os termos são percebidos pelos enfermeiros origina-se do pressuposto que estes compreendem educação permanente como responsabilidade da instituição empregatícia e que as ações de educação continuada e em serviço são confundidas e estanques, e por isto não causam o impacto necessários a melhoria da qualidade da assistência.

Portanto entende-se que a educação permanente, continuada e em serviço, podem motivar a transformação pessoal e profissional do sujeito, buscando alternativas para minimizar as dificuldades existentes na realidade de ensino do hospital-escola e da unidade de ensino, pensando numa enfermagem com propósitos e objetivos comuns, que devem ser alcançados por todos os integrantes.

As autoras justificam a realização deste estudo considerando a vivência das mesmas como docentes em instituições que contemplam unidades de saúde, de ensino profis-sionalizante e superior, e hospital-escola, que, dentre inúmeras funções, visa à obtenção de condições favoráveis ao desenvolvimento profissional, para a melhoria da qualidade dos serviços prestados, assim como à integração entre academia e serviço. Para tanto, acreditam que o enfermeiro necessita de instrumentos para continuar a aprender, assim, com a discussão sobre a educação permanente, continuada e em serviço, tem-se a intenção de contribuir para subsidiar essa questão e oferecer melhores condições de atuação profissional, com conseqüente melhoria dos serviços de saúde.
Desse modo, percebe-se a educação como um processo dinâmico e contínuo de construção do conhecimento, por intermédio do desenvolvimento do pensamento livre e da consciência crítico-reflexiva, e que, pelas relações humanas, leva à criação de compromisso pessoal e profissional, capacitando para a transformação da realidade.

Ao relacionar essa concepção de educação com a profissão de enfermagem, considerada também como prática social, compreende-se que, em todas as ações de enfermagem, estão inseridas ações educativas. Assim sendo, há necessidade de promover efetivas oportunidades de ensino, fundamentadas na conscientização do valor da educação como meio de crescimento dos profissionais da enfermagem, bem como o reconhecimento deles pela função educativa no desenvolvimento do processo de trabalho, pois para estes o conhecimento é um valor necessário do agir cotidiano e este embasa as suas ações ${ }^{(3)}$.

Nesse horizonte, cabe reafirmar que, no contexto da prática e do desenvolvimento profissional, a questão educativa
Frente ao exposto, o objetivo é discutir a educação permanente, continuada e em serviço, junto aos enfermeiros de um hospital de ensino.

\section{REFERENCIAL TEÓRICO}

A educação permanente surge como uma exigência na formação do sujeito, pois requer dele novas formas de encarar o conhecimento. Atualmente, não basta 'saber' ou 'fazer', é preciso 'saber fazer', interagindo e intervindo, e essa formação deve ter como características: a autonomia e a capacidade de aprender constantemente, de relacionar teoria e prática e vice-versa, isto refere-se à inseparabilidade do conhecimento e da ação ${ }^{(4)}$.

A educação permanente, baseada no aprendizado contínuo, é condição necessária para o desenvolvimento do sujeito, no que tange ao seu auto-aprimoramento, direcionadoo à busca da competência pessoal, profissional e social, como uma meta a ser seguida por toda a sua vida. A diversi- 
dade de informações, bem como a ampla gama de necessidades de conhecimento nas mais diversas áreas, leva à constatação de que seria tarefa quase impossível para a educação formal garantir uma adequada formação ao sujeito. Neste sentido, ela é um compromisso pessoal a ser aprendido, conquistado com as mudanças de atitudes decorrentes das experiências vividas, por meio da relação com os outros, com o meio, com o trabalho, buscando a transformação pessoal, profissional e social. A educação permanente consiste no desenvolvimento pessoal que deve ser potencializado, a fim de promover, além da capacitação técnica específica dos sujeitos, a aquisição de novos conhecimentos, conceitos e atitudes. É, portanto, intrínseca, uma capacidade a ser desenvolvida, uma competência, é o aprender constante em todas as relações do sujeito.

As reflexões acima se fundamentam no conceito da Organização das Nações Unidas para a Educação, Ciências e Cultura (UNESCO), que descreve educação permanente, a partir do princípio de que o homem se educa à vida inteira, atentando para o seu desenvolvimento pessoal e profis-sional, a evolução das capacidades, motivações e aspirações e que as suas necessidades nem sempre são de caráter emergente ${ }^{(5)}$.

Outro aspecto importante a ser considerado é a denominação educação continuada, entendida como toda ação desenvolvida após a profissionalização com propósito de atualização de conhecimentos e aquisição de novas informações e atividades de duração, definida por meio de metodologias formais ${ }^{(6)}$.

A educação continuada é conceituada como o conjunto de experiências subseqüentes à formação inicial, que permitem ao trabalhador manter, aumentar ou melhorar sua competência, para que esta seja compatível com o desenvolvimento de suas responsabilidades, caracterizando, assim, a competência como atributo individual ${ }^{(7)}$. Ela é um conjunto de práticas educativas contínuas, destinadas ao desenvolvimento de potencialidades, para uma mudança de atitudes e comportamentos nas áreas cognitiva, afetiva e psicomotora do ser humano, na perspectiva de transformação de sua prática ${ }^{(8)}$.

Para uma efetiva educação continuada, faz-se necessário direcioná-la ao desenvolvimento global de seus integrantes e da profissão, tendo como meta a melhoria da qualidade da assistência de enfermagem. Assim, essa tarefa não se resume a ensinar, pois engloba desenvolver no profissional de enfermagem uma consciência crítica e a percepção de que ele é capaz de aprender sempre, por meio da educação permanente, e motivá-lo a buscar, na sua vida profissional, situações de ensino-aprendizagem. Corroborando com este contexto, no I Seminário de Educação Continuada em Enfermagem, promovido pela Sociedade Brasileira de Enfermagem (ABEn), na década de oitenta, entende-se que a educação continuada significa a aquisição progressiva de competências, que devem ser visíveis na qualidade do exercício da assistência de enfermagem ${ }^{(9)}$.
Na organização dos projetos sobre educação continuada na enfermagem, devem-se considerar prioritários os eventos relacionados à área e os programas de admissão, atualização, treinamento, pós-graduação, pesquisa, gerência e integração docência-assistência, todos conduzidos e fundamentados no cuidado humano.

Ainda, fortalece essa concepção sobre educação continuada a Organização Panamericana da Saúde (OPS), segundo a qual a educação continuada é um

processo dinâmico de ensino aprendizagem, ativo e permanente, destinado a atualizar e melhorar a capacidade de pessoas, ou grupos, face à evolução científico-tecnológica, às necessidades sociais e aos objetivos e metas institucionais ${ }^{(10)}$.

Para que tais pressupostos sejam seguidos, as estruturas de educação continuada existentes nas organizações devem criar espaços de discussão, propor estratégias e alocar recursos, proporcionando que os trabalhadores dominem as situações, a tecnologia e os saberes do seu tempo e do seu ambiente, para possibilitar o pensar e a busca de soluções criativas para os problemas.

Neste contexto a pesquisa é apontada como uma das ferramentas que podem colaborar nesse processo $^{(11)}$, pois ela tanto auxilia na validação de práticas já consagradas, qualificando o seu uso no cotidiano, como na transformação crítica do presente, pela possibilidade de apontar as mudanças necessárias.

Inserida nesse cenário de aprendizagem também está a educação em serviço, caracterizando-se como um processo educativo a ser aplicado nas relações humanas do trabalho, no intuito de desenvolver capacidades cognitivas, psicomotoras e relacionais dos profissionais, assim como seu aperfeiçoamento diante da evolução científica e tecnológica. Dessa maneira, ela eleva a competência e valorização profissional e institucional.

A educação em serviço é considerada como um tipo de educação cujo desenvolvimento processa-se no ambiente de trabalho, voltada para uma instituição em particular ${ }^{(12)}$.

Nesse âmbito, destaca-se a importância da educação em serviço para a enfermagem, como sendo um dos esteios para a assistência eficaz ao paciente, pois, por meio

de um processo educativo atualizado e coerente com as necessidades específicas da área, ela mantém o seu pessoal valorizado e capaz de apresentar um bom desempenho profissional(13).

$\mathrm{Na}$ educação em serviço, podem destacar quatro áreas de atuação, que são a orientação ou introdução ao trabalho; treinamento; atualização; e aperfeiçoamento, aprimoramento ou desenvolvimento.

Considerando as questões explanadas, percebe-se que, na educação em serviço, os projetos de ensino devem estar 
em consonância com os interesses de todos os envolvidos, ou seja, devem atender aos anseios e às necessidades daqueles que deles vão participar, aos objetivos da instituição e, no caso específico da enfermagem, à finalidade do trabalho, que é a melhoria da assistência de enfermagem. Apesar da distinção entre os termos educação permanente, continuada e em serviço, todas têm caráter de continuidade do processo educativo, mas se fundamentam em diferentes princípios metodológicos. Entende-se também que a educação permanente é mais ampla, por fundamentar-se na formação do sujeito, enquanto a educação continuada e a em serviço estão contidas na permanente, num contexto de complementaridade.

\section{MÉTODO}

A pesquisa é de natureza qualitativa e busca a compreensão do tema pesquisado, favorecendo o processo de descobrimento, por meio de análise, síntese de idéias e conceitos, com envolvimento de aspectos emocionais e contextuais.

A técnica escolhida para a coleta de dados foi o grupo focal, visto que é uma metodologia exploratória, no intento de prover a compreensão das percepções, dos sentimentos, das atitudes e motivações ${ }^{(14)}$. Esta permite ao investigador verificar como as pessoas avaliam uma experiência, idéia ou um evento, como definem um problema e quais opiniões, sentimentos e significados encontram-se associados a esse problema. Sob essa ótica, o grupo focal apresenta caráter exploratório e avaliativo, voltado à compreensão de dimensões subjetivas do coletivo, acerca do tema de estudo. Esta técnica de pesquisa qualitativa prevê a obtenção de dados por meio de discussões em grupo, nas quais cada participante expressa sua percepção, suas crenças, seus valores, suas atitudes e representações sociais sobre o tema estudado ${ }^{(15)}$. O grupo focal deve estar centrado em ouvir as opiniões e experiências de cada participante $^{(16)}$.

Os sujeitos nesta pesquisa foram nove enfermeiros, com no mínimo um ano de atuação no serviço e/ou ensino no hospital universitário, em diferentes funções: assistenciais, coordenadores, docentes de curso de graduação e curso técnico em enfermagem. A diversidade na composição do grupo focal visa permitir a identificação e a compreensão de diferenças de percepção sobre o tema ${ }^{(15)}$.

Visando a busca por esclarecimentos que fundamentem os objetivos do estudo, os debates do grupo focal devem ser conduzidos por um guia de temas, cuja finalidade é propiciar uma investigação produtiva, ele consiste em questões a serem trabalhadas nas reuniões, com o propósito de nortear a discussão.

Na elaboração do guia de temas, procurou-se relacionar os objetivos da pesquisa aos questionamentos feitos aos enfermeiros, assim, para discutir sobre educação permanente, continuada e em serviço, buscou-se, nas duas primeiras sessões, identificar os fatores intervenientes no processo educativo, dentro do processo de trabalho do enfermeiro. A terceira sessão teve como objetivo descrever fatores que facilitam ou dificultam o desenvolvimento da educação no ambiente do trabalho. Na quarta sessão, discutiu-se a diferenciação dos termos educação permanente, continuada e em serviço. Durante a quinta sessão, a proposta foi delinear o conceito de educação permanente num hospital escola, e a sexta e última sessão visou à proposição de diretrizes para o desenvolvimento da educação permanente.

Os dados foram coletados no período de outubro a dezembro de 2003, durante as seis reuniões do grupo focal, por meio do recurso de gravação (imagem e vídeo), além dos registros realizados pela coordenadora/moderadora e pela observadora das sessões, com a finalidade de obter todas as expressões verbais e corporais possíveis dos sujeitos do estudo, visando conseguir uma transcrição de dados fidedigna e possibilitar a compreensão deles pela temática pesquisada.

A partir da transcrição dos dados, obtida por meio de cópia rigorosa das expressões verbais, realizou-se a análise pela técnica do Discurso do Sujeito Coletivo (DSC) ${ }^{(17)}$. A proposta dos autores é reconstruir com pedaços de discursos individuais, como em um quebra-cabeça, tantos discursos-síntese quantos se julguem necessários para expressar uma dada 'figura', ou seja, um dado pensar ou uma representação social de um fenômeno. Observa-se que, apesar desta técnica envolver várias pessoas falando, não se trata de um nós, mas de um eu coletivizado.

O projeto foi aprovado pelo Comitê de Ética em Pesquisa da Sociedade Evangélica Beneficente de Curitiba, que analisou e aprovou a pesquisa, na qual para a coleta de dados respeitou-se os princípios éticos, em conformidade com a Resolução 196/96 do Ministério da Saúde, reservando todos os direitos da equipe e da instituição, garantindo aos participantes a liberdade de recusar a participar, ou retirar seu consentimento no decorrer do trabalho.

\section{APRESENTAÇÃOE DISCUSSÃO DOS RESULTADOS}

Os dados obtidos nas sessões do grupo focal e analisados pela técnica do discurso do sujeito coletivo, que versam sobre a educação permanente, continuada e em serviço, são relatados a seguir.

O discurso do enfermeiro descreve que:

a busca do conhecimento deve ser uma habilidade interna, desenvolvida natural e constantemente. Quando isso 
não ocorre, o estímulo para a mudança vem da necessidade de crescer, da exigência do mercado de trabalho, do avanço tecnológico, e ele é encontrado nas relações da família, do trabalho, da escola, dialogando-se constantemente. A partir de um estímulo inicial, essa busca de conhecimento torna-se um hábito incorporado e realimentado por meio da qualidade da assistência prestada, pela aquisição da autoconfiança, pelo respeito pessoal e profissional, levando o profissional a ousar e, conseqüentemente, a buscar cada vez mais conhecimento.

Para justificar e fundamentar as questões relatadas no discurso do enfermeiro sobre o processo educativo encontra-se base na definição de educação, descrita como toda modalidade de influências e inter-relações que convergem para a formação de traços de personalidade social e do caráter, implicando uma concepção de mundo, ideais, valores, modos de agir, que se traduz em convicções ideológicas, morais, políticas e princípios de ação frente a situações e desafios da vida prática ${ }^{(18)}$.

Neste sentido entende-se que a educação origina-se em todas as experiências vivenciadas pelo sujeito nas diversas situações que se apresentam, portanto, a educação implica na busca constante do homem pela construção do seu conhecimento, procurando meios que o levem ao crescimento e aperfeiçoamento de seu saber.

O Discurso do enfermeiro sobre o termo educação permanente diz que esta é percebida

como a educação do início ao fim da vida, com o nascimento começa a aprendizagem e continua até o fim, durante todo o processo de formação. Ela é intrínseca à pessoa, é a busca pelo conhecimento, por novas informações, e move-se por duas razões: aprimoramento pessoal e exigência do trabalho, sendo que, em qualquer uma das formas, leva a aquisição de conhecimentos novos e sua aplicação. É constituída na formação geral escolar.

Essa definição de educação permanente leva ao entendimento de que o enfermeiro deve ter no auto-aprimoramento, direcionado à busca da competência pessoal e profissional, uma meta a ser seguida por toda a sua vida. A variedade de informações, bem como a ampla gama de necessidades de conhecimento nas mais diversas áreas, leva à constatação de que seria tarefa quase impossível para a educação formal garantir uma adequada formação do sujeito.

\section{O enfermeiro compreende que}

a educação permanente engloba a educação continuada e a em serviço, respectivamente, uma formal e outra informal, complementando as necessidades do profissional. As duas formam a educação permanente, pois a pessoa está permanentemente adquirindo e construindo conhecimento. Está relacionada ao profissionalismo, compromisso e envolvimento com a profissão, bem como ao prazer pelo trabalho, conduzindo ao desejo de estar sempre atualizado, informado e evoluindo profissionalmente. Além dis- so, há a exigência do mercado de trabalho, que seleciona os melhores profissionais.

Com este entendimento de que a educação permanente integra a educação continuada e em serviço, o enfermeiro compreende que todas possuem caráter de continuidade de aprendizagem, entretanto desenvolvem-se em diferentes metodologias.

Assim, o desenvolvimento da educação permanente leva o profissional enfermeiro à competência, ao conhecimento e à atualização, que são componentes necessários para garantir a sobrevivência, tanto do profissional quanto da própria profissão.

Complementa-se a exposição desse desafio e dessas mudanças referenciando que

as revoluções tecnológicas e administrativas já não deixam alternativas senão a de segui-las com a mesma rapidez que as caracterizam. Todos os dias, a mudança alcança as pessoas e organizações, de forma gradual e global; pelos seus impactos, sente-se necessidade de se preparar para elas ${ }^{(19)}$.

O modo para desenvolver esta educação segundo descreve o enfermeiro é

iniciar a conscientização desse longo processo educativo na formação acadêmica, desde seu início, demonstrando a realidade que o profissional vai vivenciar, as cobranças, as tensões e a concepção de que um bom enfermeiro é uma sumidade, com domínio da situação e do conhecimento.

Para que isso ocorra, o aluno necessita aprender a buscar conhecimento, e não a recebê-lo pronto, como é característica do ensino hoje. Por meio do estímulo, da motivação e da sensibilização, leva-se à conscientização e à mudança de atitude do aluno em relação à busca de conhecimento.

O discurso ressalta que, para os enfermeiros assumirem a responsabilidade por sua educação permanente, eles devem ser motivados e incentivados durante a graduação, mediante um ensino mais problematizador, reconhecendo, contudo, que isso é apenas o início do aprendizado, que deverá desenvolver-se ao longo da vida.

Esta reflexão veio ao encontro da compreensão das autoras sobre a educação permanente como um compromisso pessoal a ser aprendido, conquistado com as mudanças de atitudes, decorrentes das experiências vividas, por meio da relação com os outros, com o meio, com o trabalho, buscando a transformação pessoal, profissional e social. A educação permanente consiste no desenvolvimento pessoal, que deve ser potencializado, a fim de promover, além da capacitação técnica específica dos trabalhadores, a aquisição de novos conhecimentos, conceitos e atitudes, tais como: visão crítica dos problemas contemporâneos e responsabilidade social e cooperação dentro e fora do ambiente de trabalho, constituindo-se em motivação para continuar a aprender. 
Sobre a educação continuada o enfermeiro revela em seu discurso que

são as informações formais, planejadas, direcionadas, aplicadas e avaliadas, de acordo com a necessidade do trabalho. A pós-graduação, as especializações e o mestrado são considerados educação continuada.

Cada vez mais, os profissionais capacitam-se por meio da educação continuada, que deve ser ministrada ou trabalhada de modo multiprofissional, pois as questões que se apresentam não são apenas ligadas à enfermagem e sim à equipe multiprofissional, ao hospital como um todo. Então, a questão educacional deve ser vista também como um todo.

Neste sentido o entendimento de educação continuada refere-se as experiências que seguem a formação inicial, com a finalidade de melhorar a competência do sujeito ${ }^{(7)}$.

Corroborando e complementando a compreensão da definição acima citada, a educação continuada é abordada como um amplo processo, que inclui a educação formal e a informal, como encontros com colegas e auto-aprendizagem, objetivando o desenvolvimento pessoal e profissional ${ }^{(20)}$. Nesse sentido, a educação continuada é responsabilidade dos serviços e das pessoas, cuja motivação propicia o uso das experiências vividas no trabalho, na família e na sociedade, para se educar continuamente. Assim, uma efetiva educação continuada na profissão de enfermagem deve ser direcionada para o desenvolvimento global de seus integrantes, tendo como meta a melhoria da qualidade da assistência. sendo

A educação em serviço é entendida pelo enfermeiro como

um trabalho diário, momentâneo, em que o enfermeiro necessita de tempo e dedicação para acompanhar no dia-adia sua equipe, e a sistematização do trabalho é fundamental para que isso ocorra.

A educação em serviço é importante no processo de trabaIho, e isso deve ser colocado para o funcionário no treinamento, na capacitação, apesar das dificuldades encontradas para incentivá-los a participar dessas atividades. Aqueles que participam são os que gostam do que fazem e são conscientes da concorrência do mercado de trabalho.

A educação em serviço dá-se pelo acúmulo de experiências, é empírica, facilitada a cada mudança de setor, quando necessitamos conhecer nova rotina, novos clientes, novas patologias, geralmente, associando o que conheço a novas situações vividas no atendimento ao cliente ou às relações interprofissionais, sem que haja planejamento, preparo ou pesquisa. Assim, a educação em serviço ocorre no momento do trabalho, conforme a necessidade de esclarecer uma situação.

Esta percepção sobre a educação em serviço fundamenta-se no entendimento que esta é caracterizada como pro- cesso educativo desenvolvido e aplicada nas inter-relações do trabalho, visando aperfeiçoamento, a melhoria da competência e a valorização profissional e institucional.

Neste contexto o enfermeiro compreende que

a relação entre educação permanente, continuada e em serviço é visualizada pela característica de continuidade que elas contêm.

Existe uma constância de aprendizagem, mas que se diferenciam entre si pela finalidade e dependerão de cada situação de ensino e de seus objetivos.

\section{CONSIDERAÇÕES FINAIS}

Ao desenvolver esta pesquisa constatou-se que os enfermeiros tiveram algumas dificuldades para diferenciar os termos educação permanente, continuada e em serviço. Contudo, após discutir a terminologia e refletir sobre ela, o grupo entendeu que há diferenças entre os termos, como demonstram os conceitos construídos pelo grupo, e que vêm ao encontro da literatura estudada.

Os enfermeiros durante as sessões do grupo focal conseguiram diferenciar a educação permanente, compreendida como intrínseca ao sujeito, desenvolvida com a formação da pessoa, seu caráter, e relacionada com as interações sociais; da educação continuada, realizada por meio de cursos, que podem ser as pós-graduações, sendo planejada, direcionada, aplicada e avaliada como uma educação formal; e da educação em serviço, que ocorre no cotidiano do processo de trabalho, por meio das experiências profissionais, pela necessidade imediata de solucionar um problema, como uma educação informal.

O enfermeiro descreveu, ainda, a educação permanente como uma habilidade desenvolvida continuamente na formação do sujeito, tendo como conseqüência o aprimoramento pessoal e profissional, diante da evolução tecnológica e as exigências do mercado de trabalho.

A diferenciação da terminologia, segundo o grupo, é importante para definir o tipo de ação a ser desenvolvida diante da necessidade educativa apresentada, fato que confirma o pressuposto do estudo, portanto, acredita-se que, há necessidade de promover efetivas oportunidades de ensino, fundamentadas na conscientização do valor da educação como meio de crescimento dos profissionais da enfermagem, bem como o reconhecimento e a conscientização deles pela função educativa, no exercício de seu processo de trabalho. Já esse processo deve estar inserido no desenvolvimento de todas as ações gerenciais, assistenciais e docentes, tornando-os profissionais mais críticos, mais envolvidos com a comunidade em que atuam, mais capacitados para transformar a realidade e conscientes de sua verdadeira função de educador. 


\section{REFERÊNCIAS}

1. Morin E. Os sete saberes necessários à educação do futuro. São Paulo: Cortez/UNESCO; 2002.

2. Freire P. Educação e mudança. Rio de Janeiro: Paz e Terra; 2001.

3. Domingues TAM, Chaves EC. O conhecimento científico como valor no agir do enfermeiro. Rev Esc Enferm USP. 2005;39(n. esp):580-8.

4. Morin E. La méthode 3: la connaissance de la connaissance. Paris: Seuil; 1990.

5. Delors J. Educação: um tesouro a descobrir. São Paulo: Cortez; 1999.

6. Paschoal AS. O discurso do enfermeiro sobre educação permanente no grupo focal [dissertação]. Curitiba: Universidade Federal do Paraná; 2004.

7. Davini MC. Practicas laborales en los servicios de salud: las condiciones del aprendizaje. In: Haddad JQ, Roschke MAC, Davini MC, editores. Educación permanente de personal de salud. Washington: Organización Panamericana de la Salud; 1994. p. 109-25. (Serie Desarrollo de Recursos Humanos, n.100).

8. Salum NC, Prado M. Educação continuada no trabalho: uma perspectiva de transformação da prática e valorização do trabalhador(a) de enfermagem. Texto Contexto Enferm. 2000;9(2 Pt1):298-311.

9. Girade MG, Cruz EMNT, Stefanelli MC. Educação continuada em enfermagem psiquiátrica: reflexão sobre conceitos. Rev Esc Enferm USP. 2006;40(1):105-10.

10. Oguisso T. A educação continuada como fator de mudanças: visão mundial. Nursing (São Paulo). 2000;3(20):22-9.
11. Castilho V. Educação continuada em enfermagem: a pesquisa como possibilidade de desenvolvimento de pessoal. Mundo Saúde. 2000;24(5):357-60.

12. Kurcgant P. Educação continuada: caminho para a qualidade. Rev Paul Enferm. 1993;12(2):66-71.

13. Dilly CML, Jesus MCP. Processo educativo em enfermagem: das concepções pedagógicas à prática profissional. São Paulo: Rode; 1995.

14. Edmunds H. The focus group research handbook. New York: McGraw-Hill; 1999.

15. Debus M. Manual para excelencia en la investigación mediante grupos focales. Washington: Academy for Educational Development; 1997.

16. Trentini M, Gonçalves LHT. Pequenos grupos de convergência: um método no desenvolvimento de tecnologia na Enfermagem. Texto Contexto Enferm. 2000;9(1):63-78.

17. Lefévre F, Lefévre AMC. O discurso do sujeito coletivo: um enfoque em pesquisa qualitativa (Desdobramentos). Caxias do Sul: EDUSCS; 2003.

18. Morin E. A cabeça bem-feita: repensar a reforma, reformar o pensamento. $8^{\text {a }}$ ed. Rio de Janeiro: Bertrand Brasil; 2003.

19. Bezerra ALQ. O contexto da educação continuada em enfermagem. São Paulo: Leomar e Martinari; 2003.

20. Leite MMJ, Pereira LL. Educação continuada em enfermagem. In: Kurcgant P, coordenadora. Administração em enfermagem. São Paulo: EPU; 1991. p. 147-63. 